\title{
The HIV-protease inhibitor saquinavir reduces proliferation, invasion and clonogenicity in cervical cancer cell lines
}

\author{
ELISABETTA BANDIERA $^{1 *}$, PAOLA TODESCHINI ${ }^{1 *}$, CHIARA ROMANI $^{1}$, \\ LAURA ZANOTTI $^{1}$, EUGENIO ERBA ${ }^{2}$, BENEDETTA COLMEGNA ${ }^{2}$, ELIANA BIGNOTTI ${ }^{1}$, \\ ALESSANDRO DAVIDE SANTIN $^{3}$, ENRICO SARTORI ${ }^{1}$, FRANCO EDOARDO ODICINO ${ }^{1}$, \\ SERGIO PECORELLI $^{1}$, RENATA ALESSANDRA TASSI ${ }^{1}$ and ANTONELLA RAVAGGI ${ }^{1}$ \\ ${ }^{1}$ Department of Obstetrics and Gynecology, 'Angelo Nocivelli' Institute for Molecular Medicine, \\ University of Brescia, I-25123 Brescia; ${ }^{2}$ Department of Oncology, Flow Cytometry Unit, \\ IRCCS - 'Mario Negri' Institute for Pharmacological Research, I-20156 Milan, \\ Italy; ${ }^{3}$ Department of Obstetrics, Gynecology and Reproductive Sciences, \\ Yale University School of Medicine, New Haven, CT 06510, USA
}

Received May 11,2016; Accepted July 26, 2016

DOI: $10.3892 / \mathrm{ol} .2016 .5008$

\begin{abstract}
Innovative therapies in cervical cancer (CC) remain a priority. Recent data indicate that human immunodeficiency virus (HIV)-protease inhibitors used in highly active antiretroviral therapy can exert direct antitumor activities also in HIV-free preclinical and clinical models. The aim of the present study was to evaluate the antineoplastic effects of various HIV-protease inhibitors (indinavir, ritonavir and saquinavir) on primary and established CC cell lines. Two CC cell lines established in our laboratory and four commercially available CC cell lines were treated with indinavir, ritonavir and saquinavir at different concentrations and for different times. Proliferation, clonogenicity and radiosensitivity were evaluated by crystal violet staining. Proteasomal activities were assessed using a cell-based assay and immunoblotting. Cell cycle was analyzed by propidium iodide staining and flow cytometric analysis. Invasion was tested with Matrigel chambers. A $t$-test for paired samples was used for statistical analysis. In all cell lines, saquinavir was more effective than ritonavir in reducing cell proliferation and inhibiting proteasomal activities $(\mathrm{P} \leq 0.05)$. Conversely, indinavir exerted a negligible effect. The saquinavir concentrations required to modulate the proteasome activities were higher than those
\end{abstract}

Correspondence to: Dr Antonella Ravaggi, Department of Obstetrics and Gynecology, 'Angelo Nocivelli' Institute of Molecular Medicine, University of Brescia, P. le Spedali Civili 1, I-25123 Brescia, Italy

E-mail: antonella.ravaggi@unibs.it

*Contributed equally

Key words: cervical cancer, HIV-protease inhibitors, saquinavir, cell lines, proteasomal activities observed to be effective in inhibiting cell proliferation. In HeLa cells, saquinavir was strongly effective in inhibiting cell invasion and clonogenicity $(\mathrm{P} \leq 0.05)$ at concentrations much lower than those required to perturb proteasomal activities. Saquinavir did not contribute to increase the sensitivity of HeLa cells to X-rays. In conclusion, the present results demonstrate that saquinavir is able to significantly reduce cell proliferation, cell invasion and clonogenicity in a proteasome-independent manner in in vitro models of $\mathrm{CC}$, and suggest that saquinavir could be a promising $\mathrm{CC}$ therapeutic agent.

\section{Introduction}

Cervical cancer (CC) is the fourth most common cancer in women, with 528,000 estimated new cases and 266,000 mortalities worldwide in 2012 (1). In particular, 86\% of mortalities caused by $\mathrm{CC}$ occur in developing countries (2), due to the absence of national CC screening programs $(3,4)$.

Persistent infection by oncogenic, high-risk (HR) strains of human papillomavirus (HPV) is strongly associated with CC development (5). The oncogenic properties of HR-HPV (including HPV16 and HPV18) have been mainly attributed to the production of two viral oncoproteins, E7 and E6 (5). The primary activity of E7 and E6 is to block the tumor suppressor functions of retinoblastoma $(\mathrm{Rb})(6)$ and p53 (7,8), respectively, by targeting them for ubiquitin-mediated proteasome degradation (9). The combination of these effects leads to a lack of G1 cell cycle arrest (p53 and Rb-mediated) and to an enhanced phase $\mathrm{S}$ entry (9).

$\mathrm{CC}$ treatment includes surgery, radiotherapy and cisplatinbased chemotherapy, alone or in combination (10). However, $35 \%$ of CC patients develop persistent or recurrent disease following treatment, and experience a poor prognosis (10). Thus, the requirement for innovative and effective therapies in refractory $\mathrm{CC}$ remains a high priority.

The incorporation of human immunodeficiency virus (HIV) protease inhibitors (PIs) into highly active antiretroviral 
therapy (HAART) has deeply changed the natural history of HIV infection (11). Furthermore, due to the HIV-PIs' efficacy in treating HIV-related Kaposi's sarcoma independently of their anti-HIV activity, the potential antitumor properties of these drugs have been successfully investigated against other solid and hematological malignancies (12). In this context, HIV-PIs may be considered a new class of drugs with multiple antitumor effects, including inhibition of tumor cell invasion and angiogenesis, induction of apoptosis, and inhibition of cell proliferation and proteasome activity (12-21). In particular, the selective inhibition of the proteasomal function could represent an effective strategy for the treatment of HR-HPV infections via E6 and E7 proteins turnover regulation. However, there are very few references about the antitumor effects of HIV-PIs in the context of CC, with only two studies focused on pre-neoplastic (22) rather than on transfected (23) cellular models.

The aim of the present study was to evaluate the antitumor effects of HIV-PIs, particularly indinavir, ritonavir and saquinavir, on CC cell lines, by analyzing cell proliferation, cell cycle, invasion, clonogenicity and radiosensitivity.

\section{Materials and methods}

$C C$ cell lines. Two primary $\mathrm{CC}$ cell lines ( $\mathrm{CC} 1$ and $\mathrm{CC} 2)$ were established in the Division of Obstetrics and Gynecology ('Angelo Nocivelli' Institute for Molecular Medicine, University of Brescia, Brescia, Italy) from primary tumors collected under approval of the Institutional Review Board of the socio-sanitary territorial agency (ASST) Civil Hospital (Brescia, Italy; study reference number, NP1284). CC patients were enrolled at the Division of Obstetrics and Gynecology (University of Brescia) between January and November 2008, and written informed consent was obtained prior to tumor specimen collection. Tumor biopsies were mechanically minced and incubated in RPMI medium (Euroclone SpA, Milan, Italy) with $0.14 \%$ collagenase type I (125 U/mg; Sigma-Aldrich; Merck Millipore, Darmstadt, Germany) and 0.01\% DNAse (2,000 kU/mg; Sigma-Aldrich; Merck Millipore) for $1 \mathrm{~h}$. Cell suspensions were cultured in keratinocyte serum-free medium (Thermo Fisher Scientific, Inc., Waltham, MA, USA) supplemented with $35-50 \mu \mathrm{g} / \mathrm{ml}$ bovine pituitary extract (Thermo Fisher Scientific, Inc.) and $5 \mathrm{ng} / \mathrm{ml}$ human epidermal growth factor (Thermo Fisher Scientific, Inc.). Cell cultures were grown at $37^{\circ} \mathrm{C}$ in an atmosphere of $5 \% \mathrm{CO}_{2}$. Subsequent to the 50 th passage, the cell lines were maintained in RPMI medium with $10 \%$ fetal bovine serum (FBS; Euroclone SpA). The epithelial purity of the cell lines was evaluated by immunocytochemical staining with antibodies against epithelial membrane antigen (EMA; clone gp 1.4; Leica Biosystems; Danaher Corporation, Washington, DC, USA) diluted at $1: 150$ (incubated at $37^{\circ} \mathrm{C}$ for $30 \mathrm{~min}$ ) and pan cytokeratin (clone MNF116; Dako, Glostrup, Denmark) diluted at $1: 100$ (incubated at $37^{\circ} \mathrm{C}$ for $30 \mathrm{~min}$ ).

The CaSki, HeLa, HT3 and C33a CC cell lines were obtained from the American Type Culture Collection (Manassas, VA, USA) and cultured in RPMI medium supplemented with $10 \%$ FBS. Cell cultures were maintained at $37^{\circ} \mathrm{C}$ with $5 \% \mathrm{CO}_{2}$.

HPV genotyping and HPV DNA status. DNA was isolated from CC cell lines with the DNeasy Blood \& Tissue kit
(Qiagen GmbH, Hilden, Germany), and HPV genotyping was performed using the Linear Array HPV Genotyping Test (Roche Diagnostics, Basel, Switzerland) following the manufacturer's protocol. The physical status of HPV DNA (integrated and/or episomal) was estimated by polymerase chain reaction (PCR) amplification of the E2 gene using type-specific primers (Table I). Go Taq ${ }^{\circledR}$ DNA Polymerase (Promega Corporation, Madison, WI, USA) was used for amplification, and 30 consecutive cycles $\left(94^{\circ} \mathrm{C}\right.$ for $30 \mathrm{sec}, 57^{\circ} \mathrm{C}$ for $30 \mathrm{sec}$ and $72^{\circ} \mathrm{C}$ for $30 \mathrm{sec}$ ) were performed.

RNA extraction and reverse transcription PCR for E6/E7 transcript expression. Total RNA was isolated from HPV DNA-positive tumor cell lines using the PureLink ${ }^{\mathrm{TM}}$ RNA Mini kit (Thermo Fisher Scientific, Inc.). RNA purity and quantity were evaluated spectrophotometrically. Total RNA was treated with Turbo DNase (Roche Diagnostics), and complementary DNA was synthesized using random hexamers according to the SuperScript ${ }^{\mathrm{TM}}$ II Reverse Transcriptase protocol (Thermo Fisher Scientific, Inc.). To verify E6/E7 transcript expression, PCR was conducted with AmpliTaq Gold ${ }^{\circledR}$ DNA Polymerase (Thermo Fisher Scientific, Inc.) on a 2720 Thermal Cycler (Applied Biosystems; Thermo Fisher Scientific, Inc.), using pairs of primers designed based on the conserved sequence regions of the HPV16 and HPV18 genotypes (Table I). HT3 cells served as HPV-negative controls.

Treatment of CC cell lines with HIV-PIs. Media containing HIV-PIs [National Institutes of Health (NIH) Acquired Immune Deficiency Syndrome (AIDS) Research and Reference Reagent Program, Germantown, MD, USA] or drug diluents (dimethyl sulfoxide for saquinavir and ritonavir, and $\mathrm{H}_{2} \mathrm{O}$ for indinavir) were added to exponentially growing cell cultures every day during the whole experimental period. For proliferation and proteasome assays, all CC cell lines were incubated with 10 and $100 \mu \mathrm{M}$ indinavir, and with ritonavir and saquinavir ranging from 5 to $40 \mu \mathrm{M}$. For cell cycle, cell invasion, clonogenicity and radiosensitivity assays, HeLa cells were incubated in the presence of 10 or $19 \mu \mathrm{M}$ saquinavir, which corresponded to 50 and $100 \%$ of the inhibitory concentration (IC) $)_{50}$ value, respectively.

HIV-PIs concentrations were set according to data reported by Hampson et al (23) about the effects of HIV-PIs on CC cell viability. In addition, experiments using the drug peak levels $(10 \mu \mathrm{M})$ detectable in plasma of HIV-PIs treated, HIV-infected individuals (24), or non-infected patients experiencing complete remission or regression of early-stage Kaposi's sarcoma with low or no toxicity (25), were included.

Proliferation assays. Cells were seeded in 96-well plates at a density of 500 cells/well for CaSki and CC1 cells, 250 cells/well for HeLa cells, 2,000 cells/well for CC2 and C33a cells, and 1,750 cells/well for HT3 cells. Cellular growth during the treatment was estimated by crystal violet staining (26) every day until the $\mathrm{CC}$ cell lines reached $\sim 80 \%$ confluence.

Proteasome assays. The three catalytic activities of the proteasome (chymotrypsin-like, trypsin-like and caspase-like) were investigated in all cell lines (27). Cells were seeded in 96-well plates, as described above for the proliferation 
Table I. Type-specific primers for the HPV E2, E6 and E7 genes of HPV16 and HPV18.

\begin{tabular}{lll}
\hline Gene name & \multicolumn{1}{c}{ Forward primer $\left(5^{\prime} \rightarrow 3^{\prime}\right)$} & \multicolumn{1}{c}{ Reverse primer $\left(5^{\prime} \rightarrow 3^{\prime}\right)$} \\
\hline HPV16 E2 & ATGGAGACTGTTTGCCAACG & TCATATAGACATAAATCCAGTAG \\
HPV18 E2 & ATGCAGACACCGAAGGAAAC & TTACATTGTCATGTATCCCAC \\
HPV16 E6 & TGATATAATATTAGAATGTGTGTACTGCAAGCAA & GCATAAATCCCGAAAAGCAAAGTCA \\
HPV18 E6 & GGTGTATAGAGACAGTATACCGCATG & TGTCTCCATACACAGAGTCTGAATAATGT \\
HPV16 E7 & GCTCAGAGGAGGAGGATGAAATAGA & GAGTCACACTTGCAACAAAAGGTT \\
HPV18 E7 & GTGAAGCCAGAATTGAGCTAGTAGT & AGAAACAGCTGCTGGAATGCT
\end{tabular}

HPV, human papillomavirus.

assays. Following treatment, cells were tested for proteasomal activity using Proteasome-Glo ${ }^{\mathrm{TM}}$ Cell-Based Assays (Promega Corporation), according to the manufacturer's protocol. Luminescence was measured using Infinite M200 (Tecan Group Ltd., Männedorf, Switzerland). A potent proteasome inhibitor treatment, $5 \mu \mathrm{M}$ MG132, was used as a positive control. Additionally, the proteasomal activity of HeLa cells was evaluated by immunoblotting on whole-cell protein extracts.

Immunoblotting. After $2 \mathrm{~h}$ of treatment with 40, 60 and $80 \mu \mathrm{M}$ saquinavir, whole HeLa cell protein extracts were prepared in $150 \mathrm{mM} \mathrm{NaCl}, 1 \%$ Nonidet-40, $50 \mathrm{mM}$ Tris- $\mathrm{HCl}$ (pH 7.5) and Halt Protease Inhibitor Cocktail (Thermo Fisher Scientific, Inc.). Cell extracts $(20 \mu \mathrm{g})$ were resolved by sodium dodecyl sulfate-polyacrylamide gel electrophoresis (NuPAGE ${ }^{\circledR}$ Novex $^{\circledR}$ 4-12\% Bis-Tris gels; Thermo Fisher Scientific, Inc.) and blotted onto polyvinylidene difluoride membranes (Bio-Rad Laboratories, Inc., Hercules, CA, USA). $\alpha$-Tubulin was used as a protein loading control. Following blocking in Tris-buffered saline containing 5\% non-fat milk, the blots were incubated with primary antibodies against $\alpha$-tubulin (dilution, 1:20,000; T5168; Sigma-Aldrich; Merck Millipore) or ubiquitin (dilution, 1:200; P4D1; Santa Cruz Biotechnology, Inc., Dallas, TX, USA) at $4^{\circ} \mathrm{C}$ for 12 hours, followed by incubation with horseradish peroxidase-conjugated secondary rabbit anti-mouse IgG (dilution, 1:10,000; catalog no., A9044; Sigma-Aldrich; Merck Millipore) at room temperature for $1 \mathrm{~h}$. Signals were detected on a BioSpectrum Imaging System (UVP, Inc., Upland, CA, USA) with the LiteAblot ${ }^{\circledR}$ EXTEND (Euroclone SpA). Images were processed with VisionWorks ${ }^{\circledR}$ LS Image Acquisition and Analysis software version 7.0.1 (UVP, Inc.).

Cell cycle analysis by flow cytometry. HeLa cells were seeded in 6-well plates (8,000 cells/well). Upon treatment, cells were counted and fixed in $70 \%$ cold ethanol prior to staining with $5 \mu \mathrm{g} / \mathrm{ml}$ propidium iodide in phosphate-buffered saline and $12.5 \mu \mathrm{l} / \mathrm{ml}$ RNAse A overnight at $4^{\circ} \mathrm{C}$. Flow cytometric cell cycle analysis was performed on a minimum of 20,000 cells using a BD FACSCalibur ${ }^{\mathrm{TM}}$ instrument (BD Biosciences, Franklin Lakes, NJ, USA) equipped with a 488-nm laser; fluorescence emission was detected using a filter for $620 \pm 35 \mathrm{~nm}$. The percentages of distribution of cells in the different phases of the cell cycle were analyzed according to the method by Bertuzzi et al (28).
Cell invasion assays. After $96 \mathrm{~h}$ of treatment, 60,000 HeLa cells were seeded in the upper compartment of a Corning BioCoat Matrigel Invasion Chamber 24-well plate (BD Biosciences) containing RPMI. The lower compartment contained RPMI with $10 \%$ FBS as chemoattractant. After $30 \mathrm{~h}$, the migrated cells were evaluated by microscopy.

Clonogenicity assay. Following 96 h of treatment, HeLa cells were seeded into 6-well plates at a density of 250 cells/well, and were treated with saquinavir or DMSO for an additional 6 days. The colonies were stained with crystal violet solution and analyzed with an Entry Level Image system (Immagini \& Computers, Bareggio, Italy). A background correction was performed, and the smallest control cell colony ( $\geq 50$ cells), was considered as the minimum value to set the cut-off point.

Radiosensitivity. After $96 \mathrm{~h}$ of treatment, HeLa cells were seeded in 6-well plates at a density of 500 cells/well, exposed to a dose of $0,2,4,6$ and 8 -Gy radiation, and treated for additional 6 days. Colonies were analyzed as described above.

Statistical analysis. All experiments were repeated three times independently, and all samples were tested in triplicate in each experiment. Student's $t$-test was used for paired samples to evaluate the differences between the means obtained from treated and non-treated cells. SPSS version 16.0 (SPSS, Inc., Chicago, IL, USA) was used for statistical analysis. $\mathrm{P}<0.05$ was considered to indicate a statistically significant difference.

\section{Results}

CC cell lines characterization. Two primary CC cell lines, $\mathrm{CC} 1$ and $\mathrm{CC} 2$, were obtained from patients with squamous $\mathrm{CC}$ and adenosquamous invasive CC (stage IB), respectively. The immunocytochemical staining with antibodies against EMA and pan cytokeratin demonstrated that the primary cultures contained $>99 \%$ of epithelial cells.

HPV DNA was detected and genotyped using Linear Array HPV Genotyping Test, which detected 37 high- and low-risk HPV genotypes, revealing the presence of HPV-16 in $\mathrm{CC} 1$ and $\mathrm{HPV}-18$ in $\mathrm{CC} 2$, and confirming the presence of HPV-16 in CaSki and HPV-18 in HeLa cells, and the absence of HPV in HT3 and C33a cells. Furthermore, this analysis excluded the presence of multiple HPV infections in all CC cell lines. 
Table II. Mean percentages of growth inhibition of cervical cancer cell lines (CaSki, CC1, HeLa, CC2, C33a and HT3) treated for $96 \mathrm{~h}$ with human immunodeficiency virus-protease inhibitors.

\begin{tabular}{|c|c|c|c|c|c|c|c|c|c|c|}
\hline \multirow[b]{2}{*}{ Cells } & \multicolumn{2}{|c|}{ Indinavir $(\mu \mathrm{M})$} & \multicolumn{4}{|c|}{ Ritonavir $(\mu \mathrm{M})$} & \multicolumn{4}{|c|}{ Saquinavir $(\mu \mathrm{M})$} \\
\hline & 10 & 100 & 5 & 10 & 20 & 40 & 5 & 10 & 20 & 40 \\
\hline CaSki & 3 & 5 & 3 & 7 & $30^{\mathrm{a}}$ & $67^{\mathrm{a}}$ & $10^{\mathrm{a}}$ & $15^{\mathrm{a}}$ & $47^{\mathrm{a}}$ & $100^{\mathrm{a}}$ \\
\hline $\mathrm{CC} 1$ & 2 & 5 & 4 & 6 & $28^{\mathrm{a}}$ & $56^{\mathrm{a}}$ & $11^{\mathrm{a}}$ & $20^{\mathrm{a}}$ & $43^{\mathrm{a}}$ & $90^{\mathrm{a}}$ \\
\hline HeLa & 6 & 8 & 4 & $15^{\mathrm{a}}$ & $40^{\mathrm{a}}$ & $77^{\mathrm{a}}$ & $10^{\mathrm{a}}$ & $17^{\mathrm{a}}$ & $56^{\mathrm{a}}$ & $100^{\mathrm{a}}$ \\
\hline $\mathrm{CC} 2$ & 0 & 1 & 5 & $14^{\mathrm{a}}$ & $22^{\mathrm{a}}$ & $25^{\mathrm{a}}$ & $13^{\mathrm{a}}$ & $18^{\mathrm{a}}$ & $40^{\mathrm{a}}$ & $95^{\mathrm{a}}$ \\
\hline C33a & 0 & 1 & $21^{\mathrm{a}}$ & $24^{a}$ & $34^{\mathrm{a}}$ & $73^{\mathrm{a}}$ & $22^{\mathrm{a}}$ & $28^{\mathrm{a}}$ & $58^{\mathrm{a}}$ & $91^{\mathrm{a}}$ \\
\hline НT3 & 0 & 5 & 8 & $14^{\mathrm{a}}$ & $40^{\mathrm{a}}$ & $60^{\mathrm{a}}$ & $21^{\mathrm{a}}$ & $26^{\mathrm{a}}$ & $58^{\mathrm{a}}$ & $100^{\mathrm{a}}$ \\
\hline
\end{tabular}

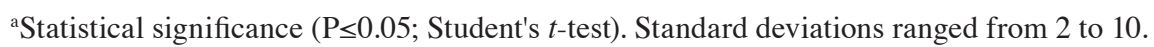

Table III. Mean percentages of proteasome inhibition of cervical cancer cell lines (CaSki, CC1, HeLa, CC2, C33a and HT3) treated for $2 \mathrm{~h}$ with human immunodeficiency virus-protease inhibitors.

\begin{tabular}{|c|c|c|c|c|c|c|c|c|c|c|c|c|}
\hline \multirow[b]{3}{*}{ Cells } & \multirow{3}{*}{$\begin{array}{l}\text { Indinavir } \\
\leq 100 \mu \mathrm{M} \\
\text { All }\end{array}$} & \multicolumn{5}{|c|}{ Ritonavir } & \multicolumn{6}{|c|}{ Saquinavir } \\
\hline & & \multirow{2}{*}{$\frac{\leq 60 \mu \mathrm{M}}{\text { All }}$} & \multicolumn{3}{|c|}{$80 \mu \mathrm{M}$} & \multirow{2}{*}{$\frac{\leq 40 \mu \mathrm{M}}{\text { All }}$} & \multicolumn{3}{|c|}{$60 \mu \mathrm{M}$} & \multicolumn{3}{|c|}{$80 \mu \mathrm{M}$} \\
\hline & & & Casp & ChyTry & Try & & Casp & ChyTry & Try & Casp & ChyTry & Try \\
\hline CaSki & 0 & 0 & 0 & 0 & 0 & 0 & 0 & 0 & 0 & $9^{a}$ & $26^{\mathrm{a}}$ & $18^{\mathrm{a}}$ \\
\hline $\mathrm{CC} 1$ & 0 & 0 & 0 & $17^{\mathrm{a}}$ & $6^{\mathrm{a}}$ & 0 & 0 & $6-10^{\mathrm{a}}$ & $10^{\mathrm{a}}$ & $37^{\mathrm{a}}$ & $47^{\mathrm{a}}$ & $43^{\mathrm{a}}$ \\
\hline HeLa & 0 & 0 & $13^{\mathrm{a}}$ & $20^{\mathrm{a}}$ & $15^{\mathrm{a}}$ & 0 & $41^{\mathrm{a}}$ & $53^{\mathrm{a}}$ & $51^{a}$ & $49^{\mathrm{a}}$ & $56^{\mathrm{a}}$ & $54^{\mathrm{a}}$ \\
\hline $\mathrm{CC} 2$ & 0 & 0 & 0 & $15^{\mathrm{a}}$ & $6^{\mathrm{a}}$ & 0 & 0 & $8^{\mathrm{a}}$ & $7^{\mathrm{a}}$ & $20^{\mathrm{a}}$ & $40^{\mathrm{a}}$ & $34^{\mathrm{a}}$ \\
\hline C33a & 0 & 0 & 0 & 0 & $14^{\mathrm{a}}$ & 0 & 0 & 0 & $10^{\mathrm{a}}$ & $20^{\mathrm{a}}$ & $33^{\mathrm{a}}$ & $35^{\mathrm{a}}$ \\
\hline HT3 & 0 & 0 & 0 & 0 & 0 & 0 & 0 & 0 & 0 & $11^{\mathrm{a}}$ & $16^{\mathrm{a}}$ & $15^{\mathrm{a}}$ \\
\hline
\end{tabular}

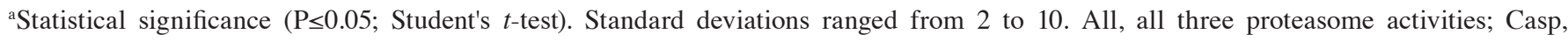
caspase-like proteasome activity; ChyTry, chymotrypsin-like proteasome activity; Try, trypsin-like proteasome activity.

According to the assumption that HPV integration disrupts the E2 gene (29), type-specific E2 PCR was performed on HPV-positive cell lines, revealing no E2 amplification in any of the samples and, thus, suggesting the complete viral integration in the host genome. HPV16/18 E6 and E7 messenger RNA was uniformly detectable, indicating that all HPV-positive cancer cell lines considered in the present study were transcriptionally active and constitutively expressed the oncogene transcripts (Fig. 1A).

HIV-PIs effects on cell proliferation. In order to test the effects of indinavir, ritonavir and saquinavir on cell proliferation, all $\mathrm{CC}$ cell lines were cultured in the presence or absence of drugs at different concentrations and for different exposure times. For all drugs, the inhibition of cell growth was directly proportional to the drug concentration and exposure time. This effect was observed in all CC cell lines, as indicated in Table II. Saquinavir was significantly more effective than ritonavir in inhibiting cell proliferation. This effect was observed in all $\mathrm{CC}$ cell lines and at all drug concentrations. On the contrary, indinavir exerted a negligible and non-significant effect on cell growth, even if used at high concentration $(100 \mu \mathrm{M})$.
HIV-PIs effects on proteasomal activities. In order to evaluate if the observed effects of HIV-PIs on cell proliferation could be correlated with a modulation of the proteasome activity, all CC cell lines were treated with saquinavir, indinavir and ritonavir under the same experimental conditions used in the above proliferation assays (Table II). Chymotrypsin-like, trypsin-like and caspase-like activities of the proteasome were analyzed by a cell-based assay. Using these experimental conditions, no effect was observed. On the contrary, when the concentrations of saquinavir and ritonavir were increased to 60 and $80 \mu \mathrm{M}$, respectively, and used to treat the cells for $2 \mathrm{~h}$, a significant modulation of proteasomal activities was observed (Table III). Treatment with $80 \mu \mathrm{M}$ saquinavir appeared to be the most effective one in inhibiting all three proteasome activities for all CC cell lines. Saquinavir at $60 \mu \mathrm{M}$ and ritonavir at $80 \mu \mathrm{M}$ inhibited the trypsin-like proteasome activity in four cell lines $(\mathrm{CC} 1$, CC2, HeLa and C33a), as well as the chymotrypsin-like proteasome activity in three cell lines (CC2, CC1 and HeLa), and the caspase-like proteasome activity only in one cell line (HeLa). Indinavir exerted a negligible and not significant effect, even if used at $100 \mu \mathrm{M}$. Of note, among the CC cell 
Table IV. Percentage of HeLa cells in various phases of the cell cycle following treatment for 24, 48, 72 and 96 h with 10 and $19 \mu \mathrm{M}$ Saq or dimethyl sulfoxide (CTRL).

Treatment duration (h)

\begin{tabular}{|c|c|c|c|c|c|c|c|c|c|c|c|c|}
\hline \multirow{3}{*}{$\begin{array}{l}\text { Phase (\% } \\
\text { of cells) }\end{array}$} & \multicolumn{3}{|c|}{24} & \multicolumn{3}{|c|}{48} & \multicolumn{3}{|c|}{72} & \multicolumn{3}{|c|}{96} \\
\hline & \multirow[b]{2}{*}{ CTRL } & \multicolumn{2}{|c|}{$\operatorname{Saq}(\mu \mathrm{M})$} & \multirow[b]{2}{*}{ CTRL } & \multicolumn{2}{|c|}{$\operatorname{Saq}(\mu \mathrm{M})$} & \multirow[b]{2}{*}{ CTRL } & \multicolumn{2}{|c|}{$\operatorname{Saq}(\mu \mathrm{M})$} & \multirow[b]{2}{*}{ CTRL } & \multicolumn{2}{|c|}{$\operatorname{Saq}(\mu \mathrm{M})$} \\
\hline & & 10 & 19 & & 10 & 19 & & 10 & 19 & & 10 & 19 \\
\hline G1 & 48 & 53 & 59 & 52 & 57 & 59 & 51 & 55 & 42 & 50 & 54 & 49 \\
\hline S & 39 & 32 & 30 & 36 & 32 & 32 & 35 & 33 & 47 & 35 & 31 & 40 \\
\hline G2-M & 13 & 15 & 11 & 12 & 11 & 9 & 14 & 12 & 11 & 15 & 15 & 11 \\
\hline
\end{tabular}

CTRL, control; Saq, saquinavir.

A

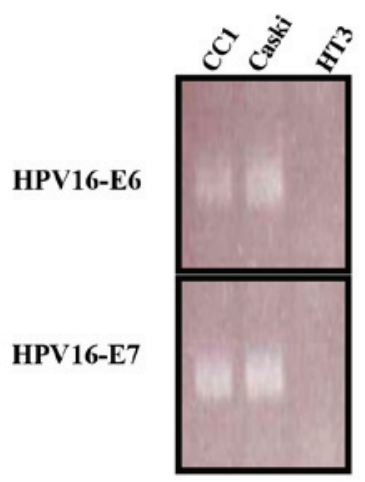

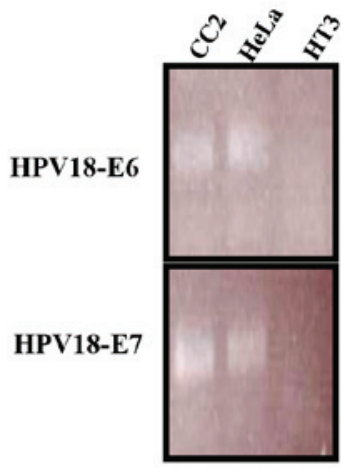

B

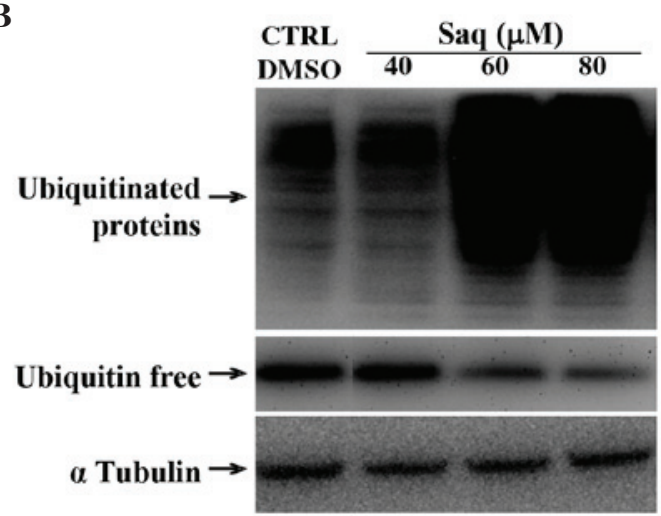

Figure 1. (A) Expression of HPV16 E6 and E7 mRNA in CC1 and CaSki cell lines, and expression of HPV18 E6 and E7 mRNA in CC2 and HeLa cell lines. The HT3 cell line served as HPV-negative control. (B) Immunoblotting for intracellular levels of ubiquitinated proteins and ubiquitin, which was performed with whole HeLa cell extracts following treatment with 40, 60 and $80 \mu \mathrm{M}$ Saq. CTRL, control; Saq, saquinavir; DMSO, dimethyl sulfoxide; HPV, human papillomavirus; mRNA, messenger RNA.

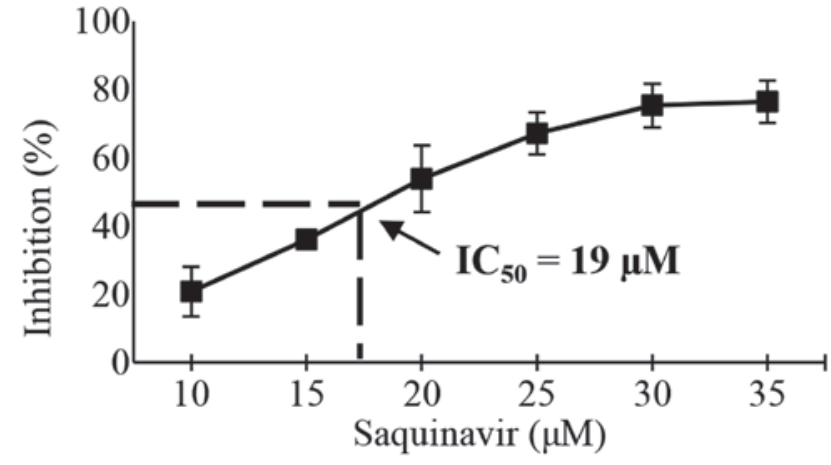

Figure 2. Dose-response curve for HeLa cells treated with saquinavir at different concentrations for $96 \mathrm{~h}$. Means and standard deviations were represented by points and error bars, respectively. $\mathrm{IC}_{50}$, inhibitory concentration.

lines, CaSki and HT3 displayed a proteasome modulation only with $80-\mu \mathrm{M}$ saquinavir treatment. As a positive control, treatment with $5 \mu \mathrm{M}$ MG132 confirmed a strong inhibition of all proteasome activities, ranging from 80 to $90 \%$ inhibition.

In order to confirm the effects of saquinavir on the proteasome activities, the levels of ubiquitinated proteins were evaluated in whole HeLa cell protein extracts by immunoblotting. Consistent with the results of the proteasome cell-based assay, treatment with indinavir or ritonavir had no or limited effects, respectively, on the proteasome (data not shown), whereas treatment with 60 or $80 \mu \mathrm{M}$ saquinavir led to increased levels of ubiquitinated proteins, indicating a significant inhibition of the proteasomal machinery, as represented in Fig. 1B. The accumulation of ubiquitinated proteins occurred with a concomitant decrease of ubiquitin. On the contrary, treatment with low concentrations of saquinavir did not reveal any significant change in the levels of ubiquitinated proteins.

Effects of saquinavir on HeLa cells. Based on the above data, saquinavir was selected as the most effective drug, and HeLa cells were selected as the most susceptible cell line, to analyze the effects of HIV-PIs on tumor cell functions, including cell invasion, cell cycle, clonogenicity and radiosensitivity. First, the $\mathrm{IC}_{50}$ of saquinavir was evaluated at $96 \mathrm{~h}$, which was the maximal time observed for HeLa cell growth in vitro. The extrapolated $\mathrm{IC}_{50}$ value was $19 \mu \mathrm{M}$ (Fig. 2). On this basis, the following experiments were performed at concentrations of saquinavir equal to 10 and $19 \mu \mathrm{M}$, corresponding to 50 and $100 \%$ of its $\mathrm{IC}_{50}$ value, respectively. 
A

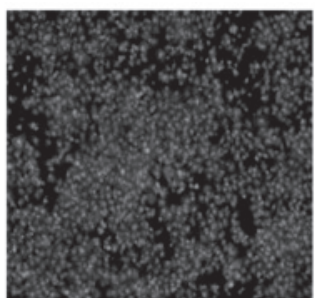

CTRL (DMSO)

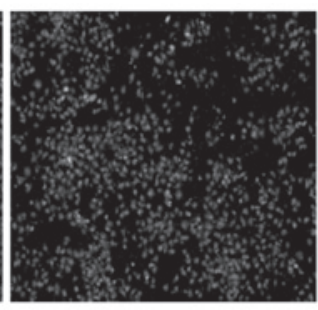

Saq $10 \mu M$

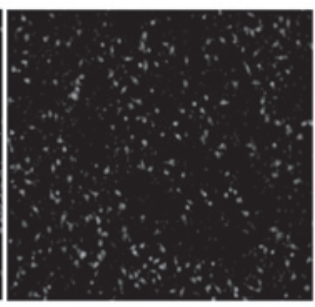

Saq $19 \mu M$

B

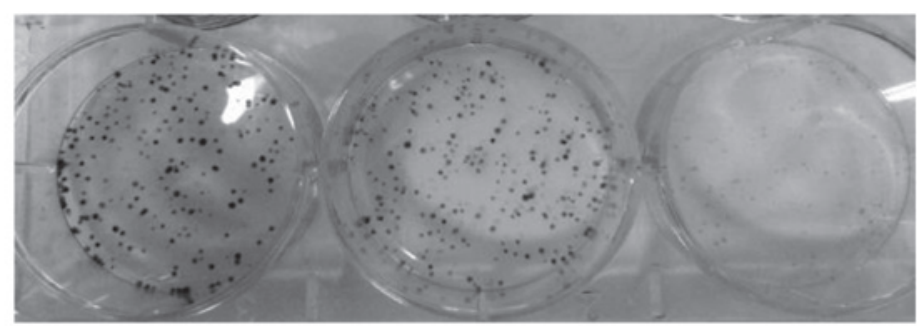

CTRL (DMSO) Saq $10 \mu \mathrm{M} \quad$ Saq $19 \mu \mathrm{M}$

Figure 3. HeLa (A) cell invasion (magnification, x10) and (B) clonogenicity upon treatment with 10 and $19 \mu \mathrm{M}$ Saq for 96 h. CTRL, control; Saq, saquinavir; DMSO, dimethyl sulfoxide.

A

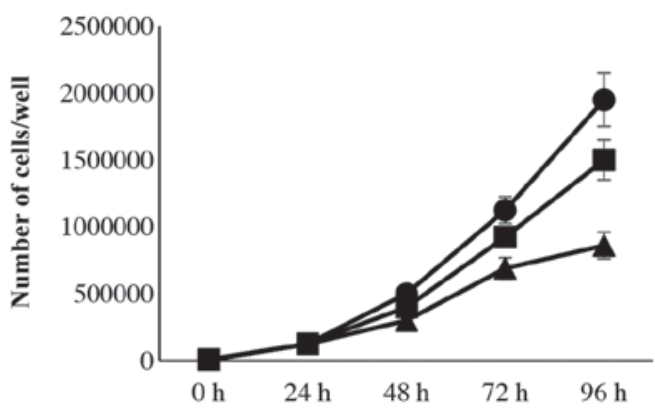

$\longrightarrow$ CTRL (DMSO) $\longrightarrow$-Saq $10 \mu \mathrm{M} \longrightarrow$ Saq $19 \mu \mathrm{M}$
B

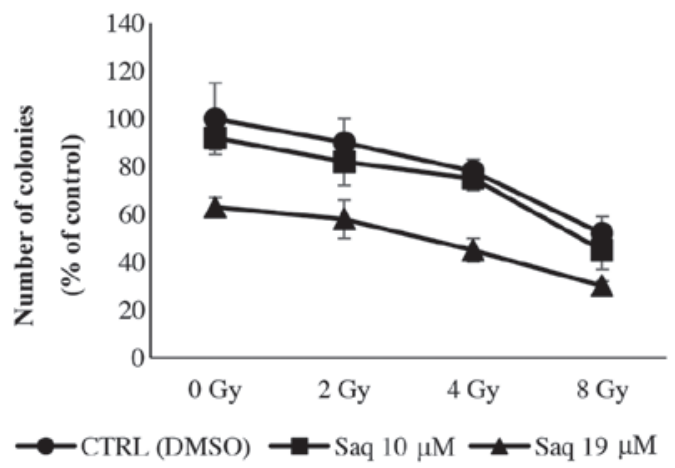

Figure 4. (A) Growth inhibitory effects induced on HeLa cells treated for 24, 48, 72 and $96 \mathrm{~h}$ with 10 and $19 \mu \mathrm{M} \mathrm{Saq.} \mathrm{(B)} \mathrm{Graphic} \mathrm{representation} \mathrm{of} \mathrm{HeLa} \mathrm{cells}$ sensitivity to X-rays following the treatment with 10 and $19 \mu \mathrm{M}$ Saq for $96 \mathrm{~h}$. Following irradiation, cells were treated with Saq for an additional 6 days. Means and standard deviations were represented by points and error bars, respectively. CTRL, control; Saq, saquinavir; DMSO, dimethyl sulfoxide.

Cell invasion. To examine the effect of saquinavir on cell invasion, a Corning BioCoat Matrigel Invasion Chamber assay was conducted to determine the ability of HeLa cells to invade through biological matrices in vitro. The treatment with saquinavir significantly inhibited FBS-promoted HeLa cell invasion by $23 \%(+/-10 \%)$ for $10-\mu \mathrm{M}$ saquinavir, and by $61 \%(+/-18 \%)$ for $19 \mu \mathrm{M}$ saquinavir $(\mathrm{P}=0.0326$ and $\mathrm{P}=0.0012$, respectively) (Fig. 3A).

Clonogenicity. Treatment of HeLa cells with saquinavir reduced their clonogenicity compared with control cells, and the effect was dose-dependent. The treatment with saquinavir inhibited cell clonogenicity by $39 \%(+/-12 \%)$ at $10 \mu \mathrm{M}$, and by $90 \%(+/-3 \%)$ at $19 \mu \mathrm{M}(\mathrm{P}=0.0052$ and $\mathrm{P}=0.0001$, respectively) (Fig. 3B).

Cell cycle. To evaluate whether growth inhibition was associated with an alteration in cell cycle phase distribution, HeLa cells were exposed to 10 or $19 \mu \mathrm{M}$ saquinavir for 24,48 , 72 and $96 \mathrm{~h}$. Saquinavir induced a growth inhibition effect in a dose-dependent manner. After $96 \mathrm{~h}$ of treatment, saquinavir at a concentration of $19 \mu \mathrm{M}$ caused a growth inhibitory effect of 56\% compared with the control cells $(\mathrm{P}=0.0012)$, while at $10 \mu \mathrm{M}$, the effect was less prominent $(\mathrm{P}=0.0481)$, being the slope of the growth curve from 48 to $96 \mathrm{~h}$ similar to that of the controls (Fig. 4A). The analysis of the cell distribution in the cell cycle phases revealed that saquinavir caused a slight delay in crossing the G1 phase of the cell cycle. At $72 \mathrm{~h}$, the highest concentration of saquinavir tested $(19 \mu \mathrm{M})$ induced a temporary accumulation in $\mathrm{S}$ phase, which was then repaired (Table IV).

Radiosensitivity. The potential effects of saquinavir were analyzed on HeLa cells exposed to increasing doses of X-rays in a clonogenic survival assay. The treatment with saquinavir at 10 or $19 \mu \mathrm{M}$ did not contribute to an increase in the sensitivity of HeLa cells to X-rays (Fig. 4B).

\section{Discussion}

Despite the use of screening programs and the improvements in therapeutic approaches, $\mathrm{CC}$ remains the fourth most lethal 
cancer among women worldwide $(1,2)$. In an effort to improve the efficacy of antitumor therapies, numerous current medical strategies are aimed at designing novel inhibitors of the relevant molecular pathways (30). In this context, the current study focused on investigating the antitumor effects of HIV-PIs, a class of drugs that reduce the incidence and/or promote the regression of AIDS-associated cancers, independently of their anti-HIV or immune-reconstituting activities (12-21). These drugs, including indinavir, saquinavir and ritonavir, have been demonstrated to target molecules with a key role in tumor progression, such as matrix metalloproteinases (MMPs) or the cellular proteasome, with antitumor effects (12-21). However, to date, the effects of HIV-PIs in CC have yet to be clarified. Accordingly, the present study evaluated the antitumor effects of indinavir, saquinavir and ritonavir in primary $\mathrm{CC}$ cell lines established in the Division of Obstetrics and Gynecology ('Angelo Nocivelli' Institute for Molecular Medicine) as well as in commercially available CC cell lines.

The present results indicated that saquinavir was more effective than ritonavir and indinavir in reducing cell proliferation and inhibiting the proteasome activities. These effects were observed in all the $\mathrm{CC}$ cell lines tested, but with a different degree of efficacy. HIV-PIs efficiency depends on the access of these drugs to intracellular sites, which is mediated by ATP-binding cassette (ABC) transporter family members such as multidrug resistant-1 and multidrug resistance-associated proteins (31). Therefore, it was speculated that a differential $\mathrm{ABC}$ transporter family expression in the present $\mathrm{CC}$ cell lines may be responsible for a different HIV-PIs intracellular accumulation and, consequently, differential efficacy.

The saquinavir concentrations required to modulate the proteasome activities were higher than those that were effective to inhibit cell proliferation. In fact, treatment with $40 \mu \mathrm{M}$ saquinavir for $96 \mathrm{~h}$ inhibited cell proliferation by $90-100 \%$ $(\mathrm{P}=0.0001)$, but it did not perturb any proteasome activity. Only the treatment with 60-80 $\mu \mathrm{M}$ saquinavir was able to reduce the proteasome functions by $10-50 \%(\mathrm{P}<0.05)$. These results are in agreement with the data of other studies conducted with similar methods, which revealed a significant proteasomal effect of these drugs only at high concentrations (15,16,32-36). In contrast, previous studies that identified lower drug levels as proteasome inhibitors, were conducted on cell extracts or purified proteasomes $(18,19,37)$. However, proteasome activity profiles obtained by cell extracts are known to be not necessarily representative of the in vivo activity patterns, thus stressing the requirement for live cell-based assays (38). Consistent with this view, the current study investigated the effects of HIV-PIs on the proteasome of intact cells. Saquinavir was selected as the most effective drug, and HeLa cells as the most susceptible cell line, to proceed with the analyses of HIV-PIs effects on tumor cell functions. Saquinavir was strongly effective in inhibiting the invasion, clonogenicity and proliferation of HeLa cells. However, the cell cycle analysis results revealed that the growth inhibition was not associated with a strong alteration in cell cycle phase distribution. This suggested that, in HeLa cells, probably saquinavir did not influence a specific cell cycle check point, but slowed down the progress of cells through all the phases of the cell cycle. Of note, the saquinavir-mediated actions on invasion, clonogenicity and cell cycle were observed at concentrations much lower (10 and $19 \mu \mathrm{M})$ than those required to perturb the proteasomal activities. Our observation of these proteasome-independent effects of saquinavir suggested its potential role in other oncogenic pathways. It is possible to speculate that saquinavir may therefore influence different $\mathrm{CC}$ cell functions modulating $\geq 1$ pathways such as Akt, signal transducer and activator of transcription 3 and $\mathrm{p} 21$, as previously reported for other tumor models $(35,36)$.

Concerning $\mathrm{CC}$, two oncoproteins produced during HR-HPV infection, E6 and E7, subvert the cell growthregulatory pathways and modify the cellular environment by labeling $\mathrm{p} 53$ and $\mathrm{Rb}$ for ubiquitin-dependent proteasomal degradation (6-9). Therefore, stabilization of p53 and Rb by preventing their degradation, could be a useful strategy to revert CC cell behavior. In the present study, saquinavir exhibited antitumor activities in a proteasome-independent way. Thus, the effects of saquinavir observed at low concentrations in the current study were likely not associated with the stabilization of $\mathrm{p} 53$ or $\mathrm{Rb}$ by proteasome inhibition.

Previous reports $(14,15)$ suggested that the ubiquitindependent proteasomal pathway plays a crucial role in enhancing radiosensitivity, by inhibiting nuclear factor $(\mathrm{NF})-\kappa \mathrm{B}$ activation. Activated $\mathrm{NF}-\kappa \mathrm{B}$ induces the expression of genes involved in protecting cells against apoptosis response to genotoxic stresses such as ionizing radiation (14). The inhibition of the ubiquitin-proteasome pathway may suppress $\mathrm{NF}-\kappa \mathrm{B}$ activation through the stabilization of the inhibitory protein inhibitor of kappa light chain gene enhancer in B cells $\alpha$, which would otherwise be degraded upon exposure to genotoxic stresses (14). Based on this hypothesis, and according to the fact that radiotherapy is frequently used in both early- and late-stage CC treatment, the potential effects of saquinavir on the sensitivity to X-rays were analyzed in the present study. It was observed that, when HeLa cells were cultured with saquinavir at 10 and $19 \mu \mathrm{M}$, the cells did not become more sensitive to X-rays. This result was consistent with the fact that the treatment of HeLa cells at these concentrations of saquinavir did not decrease their proteasomal activities.

In conclusion, to the best of our knowledge, the present is the first study evaluating the potential effects of three HIV-PIs in primary and established CC cell lines, comprehensively investigating the proteasome functions. The present study demonstrated that saquinavir is active and may consistently reduce proliferation, cell invasion and clonogenicity in a proteasome-independent way in $\mathrm{CC}$ cell lines. Considering the saquinavir dose-dependent effect observed in the present cell lines, additional studies evaluating its concentration in $\mathrm{CC}$ tissues in vivo in $\mathrm{HIV}^{+}$patients receiving HAART therapy are warranted prior to potentially translating the present findings in a novel treatment strategy for $\mathrm{HPV}^{+} \mathrm{HIV}^{-} \mathrm{CC}$ patients with disease resistant to standard treatment modalities.

\section{Acknowledgements}

HIV-PIs were a kind gift of the NIH AIDS Research and Reference Reagent Program (Germantown, MD, USA). The present study was supported by grants from the Italian Ministry of Health, Oncology Research 2006 (Rome, Italy; grant no. RF-ISS-2006-406810) awarded to S.P. 


\section{References}

1. Ferlay J, Soerjomataram I, Dikshit R, Eser S, Mathers C, Rebelo M, Parkin DM, Forman D and Bray F: Cancer incidence and mortality worldwide: Sources, methods and major patterns in GLOBOCAN 2012. Int J Cancer 136: E359-E386, 2015.

2. Arbyn M, Castellsagué X, de Sanjosé S, Bruni L, Saraiya M, Bray $\mathrm{F}$ and Ferlay J: Worldwide burden of cervical cancer in 2008. Ann Oncol 22: 2675-2686, 2011.

3. Lăără E, Day NE and Hakama M: Trends in mortality from cervical cancer in the Nordic countries: Association with organised screening programmes. Lancet 1: 1247-1249, 1987.

4. Hakama $\mathrm{M}$ and Louhivuori $\mathrm{K}$ : A screening programme for cervical cancer that worked. Cancer Surv 7: 403-416, 1988.

5. Bodily J and Laimins LA: Persistence of human papillomavirus infection: Keys to malignant progression. Trends Microbiol 19: 33-39, 2011.

6. Münger K, Werness BA, Dyson N, Phelps WC, Harlow E and Howley PM: Complex formation of human papillomavirus E7 proteins with the retinoblastoma tumor suppressor gene product. EMBO J 8: 4099-4105, 1989.

7. Scheffner M, Werness BA, Huibregtse JM, Levine AJ and Howley PM: The E6 oncoprotein encoded by human papillomavirus types 16 and 18 promotes the degradation of $\mathrm{p} 53$. Cell 63: 1129-1136, 1990.

8. Crook T, Tidy JA and Vousden KH: Degradation of p53 can be targeted by HPV E6 sequences distinct from those required for p53 binding and trans-activation. Cell 67: 547-556, 1991.

9. Boyer SN, Wazer DE and Band V: E7 protein of human papilloma virus-16 induces degradation of retinoblastoma protein through the ubiquitin-proteasome pathway. Cancer Res 56: 4620-4624, 1996.

10. DiSaia PJ and Creasman WT (eds): Cervical Cancer. In: Clinical Gynecologic Oncology. 5th edition. Mosby, Maryland Heights, pp1-106, 1997.

11. Deeks SG, Smith M, Holodniy M and Kahn JO: HIV-1 protease inhibitors. A review for clinicians. JAMA 277: 145-153, 1997.

12. Sgadari C, Barillari G, Toschi E, Carlei D, Bacigalupo I, Baccarini S, Palladino C, Leone P, Bugarini R, Malavasi L, et al: HIV protease inhibitors are potent anti-angiogenic molecules and promote regression of Kaposi sarcoma. Nat Med 8: 225-232, 2002.

13. Monini P, Sgadari C, Toschi E, Barillari G and Ensoli B: Antitumour effects of antiretroviral therapy. Nat Rev Cancer 4: $861-875,2004$

14. Russo SM, Tepper JE, Baldwin AS Jr, Liu R, Adams J, Elliott P and Cusack JC Jr: Enhancement of radiosensitivity by proteasome inhibition: Implications for a role of NF-kappaB. Int J Radiat Oncol Biol Phys 50: 183-193, 2001.

15. Pajonk F, Himmelsbach J, Riess K, Sommer A and McBride WH: The human immunodeficiency virus (HIV)-1 protease inhibitor saquinavir inhibits proteasome function and causes apoptosis and radiosensitization in non-HIV-associated human cancer cells. Cancer Res 62: 5230-5235, 2002.

16. Gaedicke S, Firat-Geier E, Constantiniu O, Lucchiari-Hartz M, Freudenberg M, Galanos C and Niedermann G: Antitumor effect of the human immunodeficiency virus protease inhibitor ritonavir: Induction of tumor-cell apoptosis associated with perturbation of proteasomal proteolysis. Cancer Res 62: 6901-6908, 2002.

17. Pati S, Pelser CB, Dufraine J, Bryant JL, Reitz MS Jr and Weichold FF: Antitumorigenic effects of HIV protease inhibitor ritonavir: Inhibition of Kaposi sarcoma. Blood 99: 3771-3779, 2002.

18. André P, Groettrup M, Klenerman P, de Giuli R, Booth BL Jr, Cerundolo V, Bonneville M, Jotereau F, Zinkernagel RM and Lotteau V: An inhibitor of HIV-1 protease modulates proteasome activity, antigen presentation, and T cell responses. Proc Natl Acad Sci USA 95: 13120-13124, 1998

19. Schmidtke G, Holzhütter HG, Bogyo M, Kairies N, Groll M, de Giuli R, Emch S and Groettrup M: How an inhibitor of the HIV-I protease modulates proteasome activity. J Biol Chem 274: 35734-35740, 1999.
20. Piccinini M, Rinaudo MT, Chiapello N, Ricotti E, Baldovino S, Mostert $\mathrm{M}$ and Tovo PA: The human 26S proteasome is a target of antiretroviral agents. AIDS 16: 693-700, 2002.

21. Goldberg AL and Rock K: Not just research tools-proteasome inhibitors offer therapeutic promise. Nat Med 8: 338-340, 2002.

22. Barillari G, Iovane A, Bacigalupo I, Palladino C, Bellino S, Leone P, Monini P and Ensoli B: Ritonavir or saquinavir impairs the invasion of cervical intraepithelial neoplasia cells via a reduction of MMP expression and activity. AIDS 26: 909-919, 2012.

23. Hampson L, Kitchener HC and Hampson IN: Specific HIV protease inhibitors inhibit the ability of HPV16 E6 to degrade p53 and selectively kill E6-dependent cervical carcinoma cells in vitro. Antivir Ther 11: 813-825, 2006.

24. Justesen US: Protease inhibitor plasma concentrations in HIV antiretroviral therapy. Dan Med Bull 55: 165-185, 2008.

25. Monini P, Sgadari C, Grosso MG, Bellino S, Di Biagio A, Toschi E, Bacigalupo I, Sabbatucci M, Cencioni G, Salvi E, et al: Clinical course of classic Kaposi's sarcoma in HIV-negative patients treated with the HIV protease inhibitor indinavir. AIDS 23: 534-538, 2009.

26. Flick DA and Gifford GE: Comparison of in vitro cell cytotoxic assays for tumor necrosis factor. J Immunol Methods 68: 167-175, 1984.

27. Tanaka K, Mizushima T and Saeki Y: The proteasome: Molecular machinery and pathophysiological roles. Biol Chem 393: 217-234, 2012.

28. Bertuzzi A, Gandolfi A, Germani A, Spanò M, Starace G and Vitelli R: Analysis of DNA synthesis rate of cultured cells from flow cytometric data. Cytometry 5: 619-628, 1984.

29. Kalantari M, Karlsen F, Kristensen G, Holm R, Hagmar B and Johansson B: Disruption of the E1 and E2 reading frames of HPV 16 in cervical carcinoma is associated with poor prognosis. Int $\mathrm{J}$ Gynecol Pathol 17: 146-153, 1998.

30. Liu J and Westin SN: Rational selection of biomarker driven therapies for gynecologic cancers: The more we know, the more we know we don't know. Gynecol Oncol 141: 65-71, 2016.

31. Lee CG, Gottesman MM, Cardarelli CO, Ramachandra M, Jeang KT, Ambudkar SV, Pastan I and Dey S: HIV-1 protease inhibitors are substrates for the MDR1 multidrug transporter. Biochemistry 37: 3594-3601, 1998.

32. Kraus M, Bader J, Overkleeft $\mathrm{H}$ and Driessen C: Nelfinavir augments proteasome inhibition by bortezomib in myeloma cells and overcomes bortezomib and carfilzomib resistance. Blood Cancer J 3: e103, 2013.

33. Kraus M, Malenke E, Gogel J, Müller H, Rückrich T, Overkleeft H, Ovaa H, Koscielniak E, Hartmann JT and Driessen C: Ritonavir induces endoplasmic reticulum stress and sensitizes sarcoma cells toward bortezomib-induced apoptosis. Mol Cancer Ther 7: 1940-1948, 2008

34. Taura M, Kariya R, Kudo E, Goto H, Iwawaki T, Amano M, Suico MA, Kai H, Mitsuya H and Okada S: Comparative analysis of ER stress response into HIV protease inhibitors: Lopinavir but not darunavir induces potent ER stress response via ROS/JNK pathway. Free Radic Biol Med 65: 778-788, 2013.

35. Gupta AK, Cerniglia GJ, Mick R, McKenna WG and Muschel RJ: HIV protease inhibitors block Akt signaling and radiosensitize tumor cells both in vitro and in vivo. Cancer Res 65: 8256-8265, 2005.

36. Ikezoe T, Saito T, Bandobashi K, Yang Y, Koeffler HP and Taguchi H: HIV-1 protease inhibitor induces growth arrest and apoptosis of human multiple myeloma cells via inactivation of signal transducer and activator of transcription 3 and extracellular signal-regulated kinase 1/2. Mol Cancer Ther 3: 473-479, 2004.

37. Laurent N, de Boüard S, Guillamo JS, Christov C, Zini R, Jouault H, Andre P, Lotteau V and Peschanski M: Effects of the proteasome inhibitor ritonavir on glioma growth in vitro and in vivo. Mol Cancer Ther 3: 129-136, 2004.

38. Berkers CR, Verdoes M, Lichtman E, Fiebiger E, Kessler BM, Anderson KC, Ploegh HL, Ovaa H and Galardy PJ: Activity probe for in vivo profiling of the specificity of proteasome inhibitor bortezomib. Nat Methods 2: 357-362, 2005. 